\title{
PRECLINICAL DETECTION OF MEN 2A GENE CARRIER USING LINKED DNA MARKERS
}

\author{
Norifumi Tanaka, ${ }^{1}$ Masayuki Yamamoto, ${ }^{1}$ Tetsuro Miki, ${ }^{2}$ Makoto OKazaki, ${ }^{1}$ \\ Isao SaKita, ${ }^{1}$ Takashi Shimotake, ${ }^{4}$ Tetsuro Kobayashi, ${ }^{1}$ \\ Akira MiYAUCHI, ${ }^{5}$ Takesada MoRI,${ }^{1}$ and Shin-ichiro TAKAl ${ }^{3}$ \\ ${ }^{1}$ Second Department of Surgery, ${ }^{2}$ Department of Geriatric Medicine, and \\ ${ }^{3}$ Department of Medical Genetics, Biomedical Research Center, \\ Osaka University Medical School, Fukushima-ku, Osaka 553, Japan \\ ${ }^{4}$ Division of Surgery, Children's Research Hospital, \\ Kyoto Prefectural University of Medicine, Sakyo-ku, Kyoto 620, Japan \\ ${ }^{5}$ Second Department of Surgery, Kagawa Medical School, \\ Miki-cho, Kagawa 761-07, Japan
}

\begin{abstract}
Summary We have performed preclinical risk estimation of multiple endocrine neoplasia type 2A (MEN 2A) by using the polymorphic DNA markers tightly linked to the MEN2A locus. The gene for MEN $2 \mathrm{~A}$ has been assigned to the pericentromeric region of chromosome 10 by linkage analysis. The preclinical detection of gene carriers in MEN 2A families using tightly linked DNA markers is useful for surgical treatment at an early stage. The DNA markers, RBP3 (retinol-binding protein 3, interstitial) and FNRB (fibronectin receptor, beta polypeptide), are both tightly linked to the MEN2A locus, and are localized to opposite sides of the MEN2A locus. We have used RBP3 and FNRB as markers for preclinical diagnosis. Of 18 Japanese families with MEN 2A, 6 families are informative for both loci, and other 10 families are informative for either RBP3 or FNRB. In one informative family, a 20-year-old female is predicted to be the gene carrier (probability; about $99 \%$ ). She should be carefully followed up till full penetrance age. We conclude that DNAbased prediction of MEN 2A is an effective procedure for clinical use.
\end{abstract}

Key Words MEN 2A, gene carriers, linked DNA markers

\section{IMTRODUCTION}

Multiple endocrine neoplasia type 2A (MEN 2A) is an autosomal dominant disease characterized by the association of medullary thyroid carcinoma (MTC),

Received January 13, 1991; revised version received February 25, 1991; Accepted February 25, 1991. 
pheochromocytoma, and adenoma or hyperplasia of the parathyroid glands. Unless MEN 2A patients receive suitable treatment, they can run an unfortunate clinical course with metastases of MTC and/or hypertensive crisis caused by pheochromocytoma. For surgical removal of the tumor to be curative, early detection of affected individuals is very important. Patients with MTC (or the pre-malignant state, C-cell hyperplasia) have an elevated basal or stimulated level of serum calcitonin. For the purpose of preclinical detection, the calcitonin stimulation test with calcium and pentagastrin injection has usually been performed on the members of MEN 2A families. Almost all the gene carriers can be detected by the screening test before the age of 40 (Gagel et al., 1982). However, the screening test is laborious and expensive.

Although the mechanism of tumorigenesis of MEN 2A has not been clarified yet, the gene for MEN 2A has been localized to the pericentromeric region of chromosome 10 by linkage studies (Mathew et al., 1987; Simpson et al., 1987; Sobol et al., 1988; Yamamoto et al., 1989). Both RBP3 and FNRB are linked to the MEN2A locus, and the MEN2A locus lies between these markers (Meyers et al., 1989). The linkage data analyzed from Japanese MEN 2A families is consistent with that of European Caucasian kindreds (Mathew et al., 1987; Simpson et al., 1987; Yamamoto et al., 1989; Meyers et al., 1989). The recombination fraction $(\Theta \mathrm{m}=\Theta \mathrm{f})$ at maximum lod scores between MEN2A and these markers is calculated to be 0.045 . for $\operatorname{RBP3}\left(Z_{\max }=13.1\right)$, and 0.063 for FNRB $\left(Z_{\max }=13.2\right)$ (Wu et al., 1990), respectively. Therefore, accurate detection of gene carriers is possible by DNA haplotype analysis using these two linked markers.

Here, we report our preliminary experience with preclinical diagnosis of MEN $2 \mathrm{~A}$ families with RBP3 and FNRB.

\section{MATERIALS AND METHODS}

Patients. We have analyzed 165 members of 18 Japanese families with MEN 2A. An individual was classified as affected if the person showed an abnormal elevation in plasma calcitonin following the stimulation test with calcium or pentagastrin and/or showed clinical evidence for MTC or pheochromocytoma.

$D N A$ analysis. DNA was prepared from peripheral blood lymphocytes, or lymphoblastoid cell lines with standard methods (Nishisho et al., 1986). DNA $(2-5 \mu \mathrm{g})$ was digested with one of various restriction endonucleases under conditions recommended by the manufacturer. Electrophoresis, transfer of DNA restriction fragments to nylon membranes (Hybond-N, Amersham), hybridization with radioactive probes, washing of filters and autoradiography were carried out as previously described (Nishisho et al., 1986). The polymorphisms detected with RBP3 (Liou et al., 1987) and FNRB (Wu et al., 1989) are listed in Table 1. RBP3 has been mapped to q11.2, and FNRB mapped to p11.2 (Meyers et al., 1989). Lod scores were calculated using the computer program LINKAGE (Lathrop, 1984) with consideration for age-dependent penetrance. 


\section{RESULTS}

Sixteen of 18 families were informative for either RBP3 or FNRB and 6 of them were informative for both markers. In our linkage data from Japanese MEN $2 \mathrm{~A}$ kindreds, maximum lod scores $\left(Z_{\max }\right)$ between MEN2A and these markers are as follows: RBP3; $Z_{\max }=5.96$, at $\Theta=0.00$ and FNRB; $Z_{\max }=4.91$ at $\Theta=0.10$ assuming $\theta \mathrm{m}=\Theta \mathrm{f}$. The one lod unit confidence interval around these markers are RBP3; 0.00-0.10, FNRB; 0.02-0.18 (95\% confidence limit).

Figure 1 shows the segregation in one informative family with MEN 2A of the marker genotypes for the RBP3 and FNRB loci. A woman (II-2) was the

Table 1. DNA polymorphic markers near the MEN2A locus. The frequencies of the polymorphic alleles in normal Japanese populations were calculated from our data. Allele frequency determined from analysis of 72 chromosomes from unrelated individuals.

\begin{tabular}{lcccc}
\hline Probe & $\begin{array}{l}\text { Restriction } \\
\text { endonuclease }\end{array}$ & Allele & $\begin{array}{l}\text { Allele } \\
\text { size (kb) }\end{array}$ & $\begin{array}{l}\text { Allele } \\
\text { frequency }\end{array}$ \\
\hline RBP3 & BglII & R & 6.3 & 0.75 \\
& & P & 4.3 & 0.25 \\
\hline FNRB & KpnI & A & 5.8 & 0.15 \\
& & B & 4.4 & 0.85 \\
& HinfI & $\mathrm{C}$ & 3.3 & 0.40 \\
& & $\mathrm{D}$ & 2.2 & 0.60 \\
\hline
\end{tabular}

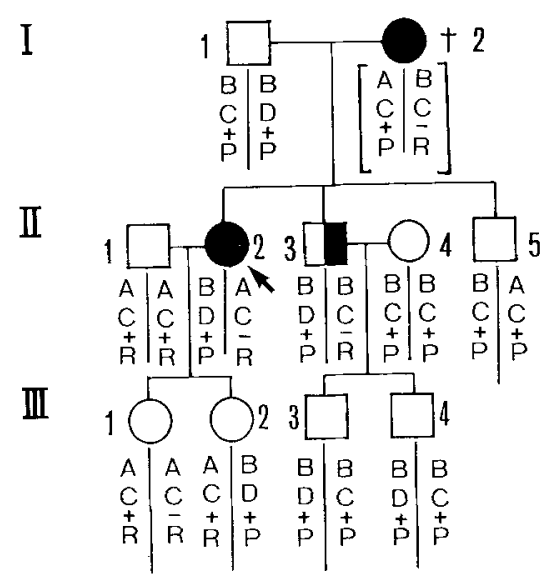

Fig. 1. Segregation of DNA haplotypes with one MEN 2A family. MEN 2A patients are demonstrated as solid symbols (MTC, right side; pheochromocytoma, left side Arrow indicates a proband. -, MEN $2 \mathrm{~A}$ affected allele; + , normal allele. 
proband, and was found through hypertensive attacks due to pheochromocytoma. Her brother (II-3) had MTC. They (II-2, II-3) had elevated serum calcitonin levels, and both underwent surgery. Their mother (I-2) who had died of metastatic pulmonary cancer seemed to be affected. We performed calcitonin stimulation test on other members of this family, but all had serum calcitonin levels within the normal range. We determined the most probable haplotypes of all members of the family. Haplotypes are shown with alleles at FNRB (KpnI), FNRB ( HinfI), MEN2A locus, and RBP3 locus downward. The woman (I-2) is already dead, but her haplotype could be deduced from haplotypes of her husband and three children. It is most likely to think that the gene for MEN 2A is segregating together with the haplotype "BCR" in the woman I-2. Her son (II-3) was affected because he had inherited haplotype "BCR" from her. Although II-2 seems to have inherited haplotype "ACR" from her mother, she was affected. This fact indicates that the crossover event had occurred between FNRB and MEN2A locus. Moreover, haplotype "ACR" in person II-2 was also inherited by one of her daughters (III-1). Therefore, the female (III-I) is predicted to be the gene carrier. From a recombination fraction between $\mathrm{MEN} 2 \mathrm{~A}$ and these markers, the risk calculation gives about $99 \%$ chance that she is the gene carrier. She is 20 years old, and we must carefully follow up by clinical data and calcitonin stimulation test.

In the other informative families, we also used the markers for improved risk estimates, but could not find other individuals likely to be presymptomatic gene carriers. A crossover between the MEN2A locus and FNRB was not detected in the other families.

\section{DISCUSSION}

In the past few years, diagnosis of genetic disease using closely linked polymorphic DNA markers has been attempted, such as cystic fibrosis and myotonic dystrophy (Antonarakis, 1989; Cooper and Schmidtke, 1987). Recently, also in MEN 2A, detecting of the carrier state by RFLP analysis was attempted (Sobol et al., 1989).

The great advantage of DNA-based estimation of the probability of a family member being a carrier of the allele for MEN 2A is its simplicity. The calcitonin stimulation test must be performed frequently until the age that the penetrance reaches almost $100 \%$, but DNA diagnosis does not have to be performed repeatedly. Then, we can select the high risk group among members of each MEN 2A family and carefully follow-up only this group with the clinical tests such as calcitonin stimulation test. Therefore, it is possible to save significantly on labor and cost. However, the genetic risk calculation by RFLPs analysis may not be feasible in every family. For instance, when the affected parent is homozygous with some DNA markers, DNA diagnosis for gene carrier is impossible. In such a case, supplementary polymorphic probes are required.

DNA-based risk estimate mainly depends on the genetic distance between 
the markers and the disease locus and on the orientation of markers and the disease locus. Recombination fractions at maximum lod scores between MEN2A and RBP3 or $F N R B$ are $\Theta \mathrm{m}=0.000, \Theta \mathrm{f}=0.097$ (RBP3) and $\Theta \mathrm{m}=0.059, \Theta \mathrm{f}=0.085(\mathrm{Wu}$ et al., 1990) (FNRB). In consideration of sex difference in recombination frequency, if a patient is informative for either RBP3 or FNRB, then the MEN2A allele can be followed with about $90 \%$ in female and almost $100 \%$ in male (RBP3), and about $91 \%$ in female and about $94 \%$ in male (FNRB) accuracy, respectively. Since RBP3 is on one side and FNRB is on the other side of the MEN2A locus, the estimated percentage of double 1ecombinations will be about $1 \%$ in females. If both markers are informative, we could gain almost $100 \%$ accuracy from males and about $99 \%$ from females.

Apparent recombination everits occurred in family A between FNRB and MEN2A locus (Fig. 1), indicating a slight degree of inaccuracy in the prediction. Given the inherently probabilistic nature of the method, the risk estimates need to be interpreted cautiously. So, the isolation and availability of additional flanking polymorphic DNA markers for the MEN2A locus would enhance the accuracy of preclinical diagnosis. Of course, the identification of the MEN 2A gene itself will allow completely accurate diagnosis. Early diagnosis and early treatment is useful for increasing the survival rate of patients with MEN 2A. Moreover, the RFLP analysis will be helpful in the calculation of risks for future generations. We conclude that DNA-based prediction is a very useful procedure for predicting the gene carriers of MEN 2A.

Acknowledgments We thank Dr. C.D.B. Bridges for providing the probe RBP3 and also thank Dr. E. Ruoslahti for the probe FNRB. We are grateful to Mrs. Y. Ebisui and Miss S. Fujita for technical assistance. We thank Prof. K.K. Kidd and A.J. Pakstis for helpful discussion.

This work was supported by a Grant-in-Aid for Special Project Research, Cancer-Bioscience, from the Ministry of Education, Science and Culture of Japan.

\section{REFERENCES}

Antonarakis, S.E. 1989. Diagnosis of genetic disorders at the DNA level. N. Engl. J. Med. 320: 153-163.

Cooper, D.N. and Schmidtke, J. 1987. Diagnosis of genetic disease using recombinant DNA. Supplement. Hum. Genet. 77: 66-75.

Gagel, R.F., Jackson, C.E., Block, M.A., Feldamann, Z.T., Reichlin, S., Hamilton, B.P. and Tashjian, A.H., Jr. 1982. Age-related probability of development of hereditary medullary thyroid carcinoma. J. Pediatr. 101 : 941-946.

Liou, G.I., Li, Y., Wang, C., Fong, S.-L., Bhattacharya, S. and Bridges, C.D.B. 1987. BglII RFLP recognized by a human IRBP cDNA localized to chromosome 10. Nucleic Acids Res. 15: 3196.

Mathew, C.G.P., Chin, K.S., Easton, D.F., Thorpe, K., Carter, C., Liou, G.I., Fong, S.-L., Bridges, C.D.B., Haak, H., Nieuwenhuijzen Kruseman, A.C., Schifter, S., Hansen, H.H., Telenius, H., Telenius-Berg, M. and Ponder, B.A.J. 1987. A linked genetic marker for multiple endocrine neoplasia type 2A on chromosome 10 . Nature 328: 527-528. 
Meyers, S., Wu, J., Goodfellow, P.J., Carson, N.L., Kidd, J.R., Anderson, L., Castiglione, C.M., Hoyle, S., Kidd, K.K. and Simpson, N.E. 1989. The locus for multiple endocrine neoplasia $2 \mathrm{~A}$ (MEN2A) is linked to two $10 \mathrm{p}$ and two $10 \mathrm{q}$ markers with an SRO of $10 \mathrm{p} 11.2$ to $10 \mathrm{q} 11.1$. HGM10. Cytogenet. Cell Genet. 51: 1050.

Nishisho, I., Miki, T., Tateishi, H., Takai, S., Motomura, K., Nakura, J., Kumahara, Y., Mori, T. and Honjo, T. 1986. Isolation of DNA clones revealing restriction fragment length polymorphisms in the human genome. Jpn. J. Human Genet. 31 : 249-258.

Simpson, N.E., Kidd, K.K., Goodfellow, P.J., McDermid, H., Meyers, S., Kidd, J.R., Jackson, C.E., Duncan, A.M.V., Farrer, L.A., Brasch, K., Castiglione, C., Gend, M., Gertner, J., Greenberg, C.R., Gusella, J.F., Holden, J.J.A. and White, B.N. 1987. Assignment of multiple endocrine neoplasia type $2 \mathrm{~A}$ to chromosome 10 by linkage. Nature $328: 528-530$.

Sobol, H., Salvetti, A., Bonnardel, C. and Lenoir, G.M. 1988. Screening multiple endocrine neoplasia type 2A families using DNA markers. Lancet 1: 62 .

Sobol, H., Narod, S.A., Nakamura, Y., Boneu, A., Calmettes, C., Chadenas, D., Charpentier, G., Chatal, J.F., Delepine, N., Delisle, M.J., Dupond, J.L., Gardet, P., Godefroy, H., Guillausseau, P.-J., Guillausseau-Scholer, C., Houdent, C., Lalau, J.D., Mace, G., Parmentier, C., Soubrier, F., Tourniaire, J. and Lenoir, G.M. 1989. Screening for multiple endocrine neoplasia type 2a with DNA-polymorphism analysis. N. Engl. J. Med. 321: 996-1001.

Wu, J., Giuffra, L.A., Goodfellow, P.J., Meyers, S., Carson, N., Anderson, L., Hoyle, L.S., Simpson, N.E. and Kidd, K.K. 1989. The beta subunit locus of the human fibronectin recepter: DNA restriction fragment length polymorphism and linkage mapping studies. Hum. Genet. 83: $383-390$.

Wu, J., Carson, N., Myers, S., Pakstis, A.J., Kidd, J.R., Castiglione, C.M., Anderson, L., Hoyle, L.S., Genel, M., Versy, M., Jackson, C.E., Simpson, N.E. and Kidd, K.K. 1990 . The genetic defect in multiple endocrine neoplasia type $2 \mathrm{~A}$ maps next to the centromere of chromosome 10. Am. J. Hum. Genet. 46: 624-630.

Yamamoto, M., Takai, S., Miki, T., Motomura, K., Okazaki, M., Nishisho, I., Tateishi, H., Honjo, T., Pakstis, A.J. and Mori, T. 1989. Close linkage of MEN2A with RBP3 locus in Japanese kindreds. Hum. Genet. 82: 287-288. 